\title{
Microalgas perifíticas como indicadoras del estado de las aguas de un humedal urbano: Jaboque, Bogotá D.C., Colombia
}

\author{
Mireya del Pilar Arcos - Pulido¹, Aura Cristina Gómez Prieto ${ }^{1}$ \\ ${ }^{1}$ División de Investigaciones, Universidad Colegio Mayor de Cundinamarca \\ Correspondencia: marcosp@unicolmayor.edu.co \\ Recibido: 17-10-06 Aceptado: 20-12-06
}

\begin{abstract}
Resumen
En el presente estudio se implementó la técnica de colonización en sustratos artificiales durante un periodo de siete meses (noviembre de 2004 a mayo de 2005). En el sector de mayor urbanización del humedal, los grupos de microalgas de mayor representatividad fueron las euglenófitas y cianófitas, con un promedio de abundancia de $20300 \mathrm{indv} / \mathrm{cm}^{2}$. En las zonas de menor intervención antrópica predominaron las diatomeas, con una abundancia promedio de $1774 \mathrm{indv} / \mathrm{cm}^{2}$. La heterogeneidad en el sistema es bastante alta debida a las condiciones tróficas y factores físicos que afectan al sistema. Los resultados mostraron diferencias espaciotemporales en términos de composición y abundancia, la contribución y sucesión de los grupos de microalgas durante las etapas de colonización igualmente fue muy diferente para cada una de las estaciones. La diversidad, composición y abundancia de las microalgas perifíticas presentes indican el proceso de eutrofización por el que atraviesa el humedal, así como, el estado de sus aguas que se encuentran medianamente contaminadas y muy contaminadas en algunos sectores.
\end{abstract}

Palabras clave: bioindicadores, contaminación, diatomeas, humedal, limnología, microalgas.

\begin{abstract}
This study implemented the technique of colonization in artificial substrates during a period of seven months (November 2004 through May 2005). In the sector of greater urbanization of the wetland, the most representative group of microalgae were the euglenophytas and cyanophytas, with abundance an average of 20300 of indv/ $\mathrm{cm}^{2}$. In the areas with lower anthropic intervention the diatoms were predominant, with an abundance average of $1774 \mathrm{ind} / \mathrm{cm}^{2}$. The heterogenity in the system is considerably high due to the trophic conditions and physical factors that affect the system. The results showed space-time differences in terms of composition and abundance. The contribution and succession of the groups of microalgae during the stages of colonization were considerably different for each one of the stations. The diversity, composition and abundance of periphytic microalgae indicates the eutrophication process the wetland is currently going through, as well as the state of its waters that are slightly polluted in some areas and highly polluted in other areas.
\end{abstract}

Keywords: bioindicators, diatomaceous, limnology, microalgae, pollution, wetland. 


\section{Introducción}

Los lagos y embalses ubicados en las áreas urbanas se enfrentan al embate de distintas actividades antrópicas, lo que genera su paulatino y constante deterioro (1). Los recursos hídricos del Distrito Capital atraviesan por una gran problemática ambiental, debida en mayor parte, a las alteraciones por contaminación y saneamiento básico $(2,3)$ que han provocado cambios en la estructura y composición de las comunidades biológicas, registrándose en numerosos cuerpos de aguas naturales, fuertes procesos de eutrofización (3).

En el Humedal de Jaboque las diversas actividades de origen antrópico y consecuentes impactos generados, difieren tanto en magnitud como intensidad a lo largo y ancho del sistema y permiten establecer una clara y necesaria zonificación espacial para efectos de su estudio y posterior manejo. La zona suroriental por ejemplo, se encuentra más afectada por la creciente urbanización del área y está delimitada físicamente por la adecuación de canales perimetrales de recolección de aguas lluvias y negras, que ingresan, sin previo tratamiento de los barrios aledaños.

El sector noroccidental ha sido el menos intervenido en cuanto a obras de infraestructura se refiere. Sin embargo, la zona de ronda es utilizada para llevar a pastar ganado vacuno y equino provocando la compactación de los suelos y contaminación hídrica. En general, el cuerpo de agua ha disminuido notablemente, en parte por la utilización de las aguas del humedal en labores de riego para los cultivos ubicados en las zonas norte y sur (4). Adicionalmente, el crecimiento exagerado de macrófitas acuáticas y la introducción de pasto kikuyo ha reducido considerablemente el espejo de agua.

Es así como la presencia y abundancia de las microalgas perifíticas que viven adheridas a sustratos vegetales, rocas o a cualquier tipo de material natural o artificial sumergido (5), pueden ser utilizadas para evaluar el estado ecológico del medio en el que se encuentran, permitiendo inferir sobre los problemas que estén sucediendo (6). Estas microalgas presentan, una alta heterogeneidad tanto espacial como temporal dependiendo de la variabilidad en los factores ambientales, red de drenaje, tipo de sustrato e hidrología, que determinan su comportamiento y distribución $(7,8,9)$.

El presente estudio se encuentra enmarcado en el convenio "Investigación aplicada en restauración ecológica en el Humedal de Jaboque" y pretende, a partir de la estructura y descripción del proceso de colonización de las microalgas perifíticas, coadyuvar, en la interpretación de su estado y dinámica actual, dado el valor ecológico y socioeconómico que representa el sistema para el vecindario y a los impactos a los que ha sido sometido en los últimos años.

\section{Materiales y métodos}

\section{Área de estudio}

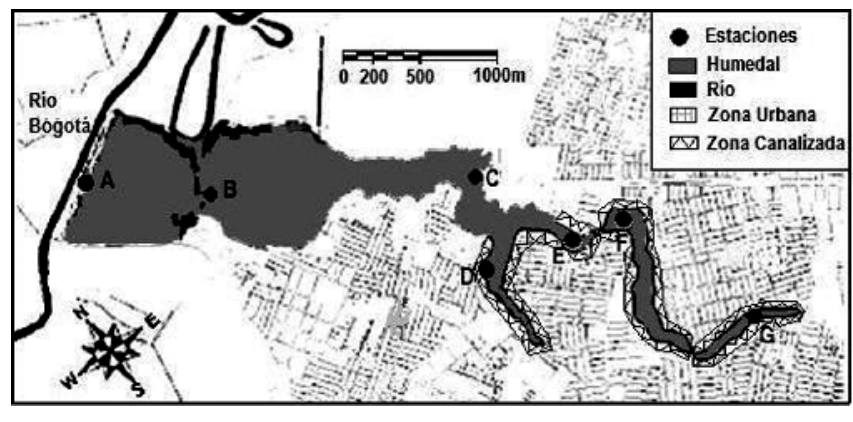

Figura 1. Estaciones de muestreo: $A, B, C, D, E, F$ y G, Humedal de Jaboque (Localidad de Engativá) Modificado de Meyer (2004) (10).

El Humedal de Jaboque se encuentra en la Localidad de Engativá, dentro del perímetro urbano del Distrito Capital (Bogotá, Colombia). Se halla limitado al

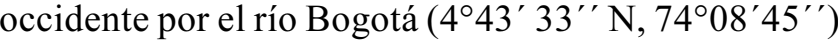
donde ingresan sus aguas; $\mathrm{y}$ al oriente, con el barrio Álamos $\left(4^{\circ} 42^{\prime} 07^{\prime \prime} \mathrm{N}, 74^{\circ} 07^{\prime} 25^{\prime \prime} \mathrm{W}\right)$. Para evaluar las consecuencias que ha tenido la intervención antrópica sobre la comunidad de microalgas perifíticas y a su vez medir el estado actual del cuerpo de agua se escogieron en total siete estaciones de muestreo, tres de estas pertenecen a la zona menos perturbada la cuál fue designada como sector uno (A, B y C), las cuatro restantes corresponden al área más afectada del humedal por la urbanización y adecuación en su 
perímetro de canales de recolección de aguas, esta zona se va a denominar sector dos (D, E, F y G) Figura 1. La selección final de los sitios se efectuó a partir de un pre-muestreo donde se tuvieron en cuenta la accesibilidad y metodología utilizada.

\section{Análisis cualitativo y cuantitativo}

Se aplicó la técnica de colonización en sustratos artificiales (7), utilizando placas de cerámica ubicadas verticalmente al sustrato para evitar una alta sedimentación y la caída de otros organismos $(7,11)$. El periodo exposición utilizado fue de dos semanas, con base en las recomendaciones para cuantificar densidades $(7,11,12)$.

Para examinar la variación espacio-temporal en términos de composición y abundancia se completaron siete meses de muestreo de noviembre de 2004 a mayo de 2005, se realizaron análisis cualitativos para la identificación de las microalgas encontradas y posterior a éstos, el conteo de individuos. El material adherido a los sustratos artificiales fue raspado $\left(48 \mathrm{~cm}^{2}\right)$ con una espátula y preservado para el análisis cualitativo con solución Transeau (agua, etanol al 90\% y formol al 40\%, en proporciones 6:3:1 respectivamente) a un volumen 1:1 de solución y $20 \mathrm{ml}$ de agua destilada (13).

Las muestras para el análisis cuantitativo fueron diluidas en $20 \mathrm{ml}$ de agua destilada y fijadas con 0.2 $\mathrm{ml}$ de lugol yodado para su preservación $(7,14)$. Para el estudio de sucesión perifítica se tomaron muestras de los sustratos instalados a la segunda, tercera, quinta y sexta semana, durante los meses de marzo y abril de 2005. Se determinaron tipo y cantidad de microalgas.

La identificación de microalgas presentes en las muestras se hizo teniendo en cuenta las claves taxónomicas de Edmondson (15), Whitford y Shumacher (16), Parra et al. (17-21), Rieradevall (22) y Cox (23). El análisis cualitativo se efectuó con ayuda de un microscopio óptico Olympus BX40 F-3. Para el análisis cuantitativo se extrajeron alícuotas de $1 \mathrm{ml}$ de la muestra, se dejaron decantar durante una hora en cámaras de sedimentación ( $24 \mathrm{~mm}$ de diámetro) y se efectuaron los conteos en un microscopio invertido (Leica MDIL IV/01) (7, 12). La cuantificación de los individuos se obtuvo mediante la fórmula propuesta por Hauer y Lamberti (24), donde la densidad se expresa en número de individuos por área de superficie $\left(\mathrm{cm}^{2}\right)$, en este caso, debido a la heterogeneidad de las muestras se realizó un conteo mínimo de 100 individuos de la especie mas representativa en las de mayor densidad y la totalidad de la muestra cuando la abundancia era muy baja.

\section{Análisis de los datos}

Los datos fueron sometidos a pruebas de normalidad y homogeneidad de varianzas (Test de Barlett's-STAT GRAPHICS v.5.0) para observar su comportamiento y proceder aplicar los análisis multivariados adecuados (25), en este caso, no paramétricos. La matriz primaria de abundancia de microalgas perifíticas fue transformada teniendo en cuenta su distribución -umbrales de la Ley de Taylor(26), el tipo de índice de asociación utilizado para los análisis de clasificación u ordenación (Bray-Curtis) y por último equiparar la importancia entre las especies más comunes y las especies raras (27). Bajo estos criterios la matriz de abundancia (indv/ $\mathrm{cm}^{2}$ ) de especies perifíticas se transformó mediante el Log $(\mathrm{x}+1)$. El método de ordenación utilizado para representar gráficamente las similitudes entre muestras fue un Ajuste Dimensional no-métrico (Nonmetric Multi-Dimensional Scaling NMDS-PRIMER v.5.0-). Esta técnica no asume linealidad entre las variables y es muy efectiva para el estudio de comunidades biológicas (28). El índice de asociación utilizado para este análisis fue el de Similitud de BrayCurtis que es bastante apropiado para datos de abundancia de especies y permite como se mencionó anteriormente, a través de las transformaciones equilibrar la contribución de especies más o menos abundantes (27). Los valores de stress que aparecen 
en cada una de las ordenaciones indican el grado de confiabilidad de la representación de similitud entre las muestras de su espacio original (multidimensional) al espacio reducido (NMDS-2 dimensiones).

Para combinar la información proporcionada por el método de ordenación utilizado (NMDS), se realizó un dendrograma (aglomeración por ligamiento promedio) a partir de la matriz de similitud mediante el Índice de Bray-Curtis (estaciones y meses-matrices tipo Q-).

Así mismo, se determinó el porcentaje de las especies que contribuyen al promedio de similitud dentro de los factores establecidos (meses -sectores) y el promedio de disimilitud entre estos (SIMilarity PERcentages -SIMPER-, PRIMER v.5.0) para obtener mayor información sobre las variables, en este caso, biológicas.

La prueba utilizada para determinar si existían diferencias estadísticamente significativas entre los rangos de similaridad de las muestras (factores espaciotemporales: sector- uno y dos - mes de muestreo) fue un Análisis de Similitud (análisis of similaritiesANOSIM- PRIMER 5.0), esta técnica es análoga a ANOVA la cual es utilizada para estadística univariada (análisis de varianza). Las matrices de similaridad para efectuar este análisis se obtuvieron a partir del Índice de Bray-Curtis. En esta caso se calcula un estadístico global -R- (análogo al F en ANOVA) para determinar si las diferencias estadísticamente significativas existen entre todos los grupos, este debe variar entre -1 a 1.

El test realiza comparaciones dentro de los grupos de muestras por parejas. En la comparación entre grupos la hipótesis nula (no existen diferencias estadísticamente significativas) fue rechazada con un nivel de significancia de $\mathrm{P}<0.05$ (999 permutaciones). En las pruebas pareadas se aplicó un nivel de significancia de 0.05/n (corrección de Bonferroni), donde $\mathrm{n}$ es el número de comparaciones pareadas posibles, esto para tener en cuenta los efectos de las diferencias en el tamaño de la muestra. Se examinó si existía interacción entre los factores para aplicar el Análisis de Similitud apropiado (ANOSIM, 2 -vías cruzado).

Para la descripción de la comunidad perifítica en términos de número de especies y proporciones que puedan indicar cambios debido a modificaciones en las condiciones ambientales o procesos biológicos se utilizó el índice de diversidad de Shannon y Weaver (1949) (bits de información) (7,12). Para observar posibles diferencias entre las diversidades obtenidas se aplicó una prueba ANOVA (análisis de varianza-1 vía) con los índices de Shannon obtenidos en cada una de las estaciones y meses de muestreo.

Finalmente, los datos de las variables fisicoquímicas medidas por Álvarez y Yepes (29) fueron sometidos al test de Kruskal-Wallis (STAT GRAPHICS v.5.0) por no cumplir con las asunciones de la estadística paramétrica, para examinar, su comportamiento a escala espacial y temporal (meses y estaciones). Las variables fisicoquímicas de la columna del agua incluidas en el análisis fueron: $\mathrm{pH}$, conductividad $\mu \mathrm{S}$ / $\mathrm{cm}$ (C), alcalinidad total mg/l (AT), dureza total mg/l (DT), fosfatos $\mathrm{mg} / \mathrm{l}$ (FA), fósforo $\mathrm{mg} / \mathrm{l}(\mathrm{FO})$, nitratos $\mathrm{mg} / \mathrm{l}$ (NTA), nitrógeno amoniacal mg/l (NA), nitrógeno total $\mathrm{mg} / \mathrm{l}(\mathrm{NT})$, sólidos suspendidos totales $\mathrm{mg} / \mathrm{l}$ (SST), sólidos totales mg/l (ST) y temperatura (T).

Los meses seleccionados para el análisis por correspondencia con las biológicas estudiadas fueron noviembre, enero, marzo y abril. En la comparación entre las estaciones y los meses de muestreo, la hipótesis nula (no existen diferencias estadísticamente significativas) fue aceptada con un nivel de significancia de $\mathrm{P}>0.05$. Para analizar las relaciones entre las variables fisicoquímicas del agua y las microalgas perifíticas se empleó la aplicación BIOENV (PRIMER v. 5.0), técnica que selecciona las variables o combinaciones de variables abióticas que mejor explican el comportamiento de los datos biológicos a partir de matrices de similitud.

El coeficiente de correlación utilizado fue el de Spearman (ñù) que oscila en un rango de -1 a 1, los 
Tabla 1. Contribución de los grupos de microalgas encontrados, (\% de abundancia), durante los meses de muestreo en el Humedal de Jaboque.

$\begin{array}{llllllll} & \text { Noviembre } & \text { Diciembre } & \text { Enero } & \text { Febrero } & \text { Marzo } & \text { Abril } & \text { Mayo } \\ \text { Euglenófitas } & 45.61 & 59.45 & 75.05 & 78.65 & 47.75 & 65.72 & 19.74 \\ \text { Clorófitas } & 18.93 & 5.15 & 5.44 & 3.74 & 27.8 & 7.05 & 7.56 \\ \text { Criptófitas } & 0.73 & 1.09 & 1.93 & 0.13 & 1.99 & 0.02 & 0.44 \\ \text { Cianófitas } & 16.39 & 8.12 & 9.98 & 0.67 & 2.74 & 18.87 & 49.26 \\ \text { Diatomeas } & 18.34 & 26.19 & 8.91 & 5.95 & 19.72 & 8.33 & 23 \\ \text { Crisófitas } & 0 & 0 & 0.31 & 0 & 0 & 0 & 0 \\ \text { Morfoespecies } & 0 & 0 & 0 & 10.86 & 0 & 0 & 0\end{array}$

valores negativos significan que existe oposición entre los datos abióticos y bióticos, así como, una parcial o completa correspondencia para los valores positivos o iguales a uno (27). Los datos fisicoquímicos del agua fueron transformados teniendo en cuenta la distribución de cada una de las variables medidas, procurando su ajuste a la normalidad para validar la matriz de similitud calculada posteriormente, en este caso, por medio del Índice de distancia Euclidiana. La matriz de similitud de especies utilizada en la misma escala temporal fue transformada con el Log $(\mathrm{x}+1)$ y calculada a partir del Índice de Bray-Curtis.

\section{Resultados}

\section{Composición y abundancia}

Se registraron 68 especies de microalgas, de las cuales 66 pertenecian a las divisiones Euglenophyta (euglenófitas), Chlorophyta (clorófilas), Cyanophyta (cianófitas), Bacillariophyta (diatomeas), Chrysophyta (crisófitas) y Cryptophyta (criptófitas). El grupo de microalgas con mayor representatividad en cuanto a número total de especies encontradas fueron las diatomeas (32.83\%) seguido de las clorófitas y euglenófitas (25.37\%) con el mismo valor, cianófitas (10.45\%), y por último las crisófitas, criptófitas y morfoespecies encontradas con el porcentaje restante $(5.96 \%)$.

El grupo más abundante y con mayor fluctuación durante el estudio fueron las euglenófitas, con valores que oscilaron entre 19.74-78.65\%, seguido de las cianófitas con un $0.67-49.26 \%$, clorófitas $3.74-27.8 \%$ y diatomeas 5.95-26.19\%. En el mes de mayo las cianófitas se destacaron con una abundancia mayor respecto al grupo de las euglenófitas con un porcentaje de 49.26. Durante la época de mayor sequía (diciembre, enero y febrero) se presentaron las morfoespecies encontradas (estación F) y los picos de mayor abundancia para el grupo de las euglenófitas, Tabla 1.

Espacialmente la composición y abundancia difiere notablemente entre las estaciones que pertenecen al sector uno (A, B y C) y las del sector dos (D, E, F y $\mathrm{G})$. En el sector uno predominan las diatomeas con valores de $42.9-83.49 \%$ mientras que el sector dos se encuentra caracterizado por la dominancia de euglenófitas y cianófitas, con porcentajes que varían de $16.49-57.60 \%$ y $2.84-40.43 \%$ respectivamente, Tabla 2.

En el análisis de ordenación Figura 2, la composición $\mathrm{y}$ abundancia de las microalgas perifíticas es muy heterogénea, mostrando una leve diferenciación espacial entre los sectores uno y dos. La variabilidad entre las estaciones es tan alta que no permite establecer patrones estacionales definidos para todo el sistema, cada sitio se comporta de forma diferente. Por ejemplo, la estación $\mathrm{G}$ en el mes de abril, exhibe una disimilitud bastante alta respecto a los meses de noviembre, enero, febrero y marzo, cuando los valores de abundancia se explican por la contribución de diferentes especies, en mayo la composición y contribución es mas similar. Las estaciones B y C ambas del sector uno difieren temporalmente con una mayor y menor abundancia respectivamente, en este 
Tabla 2. Contribución de los grupos de microalgas encontrados, (\%de abundancia), en cada una de las estaciones de muestreo en el Humedal de Jaboque.

$\begin{array}{llllllll} & \text { A } & \text { B } & \text { C } & \text { D } & \text { E } & \text { F } & \text { G } \\ \text { Euglenófitas } & 11.5 & 6.52 & 15.26 & 54.24 & 16.49 & 57.60 & 52.79 \\ \text { Clorófitas } & 1.37 & 0.54 & 11.10 & 3.70 & 16.77 & 9.66 & 7.11 \\ \text { Criptófitas } & 2.99 & 0.092 & 23.77 & 0.32 & 9.07 & 0 & 0 \\ \text { Cianófitas } & 11.3 & 9.36 & 6.96 & 2.84 & 40.43 & 17.05 & 39.13 \\ \text { Diatomeas } & 71.38 & 83.49 & 42.90 & 23.63 & 17.24 & 15.63 & 0.97 \\ \text { Crisófitas } & 0 & 0 & 0 & 15.27 & 0 & 0 & 0 \\ \text { Morfoespecies } & 0 & 0 & 0 & 0 & 0 & 0.059 & 0\end{array}$

Tabla 3. Resultados ANOSIM (2 vías-cruzado) para abundancias de especies.

$\begin{array}{lll}\text { Grupos } & \text { RGlobal } & \text { P-valor } \\ \text { Sectores (unoy dos) } & 0.207 & 0.034 \\ \text { Meses } & 0.079 & 0.133\end{array}$

*Transformación $\log (x+1)$ de los datos crudos, (999 permutaciones, $\mathrm{P}=0.05)$.
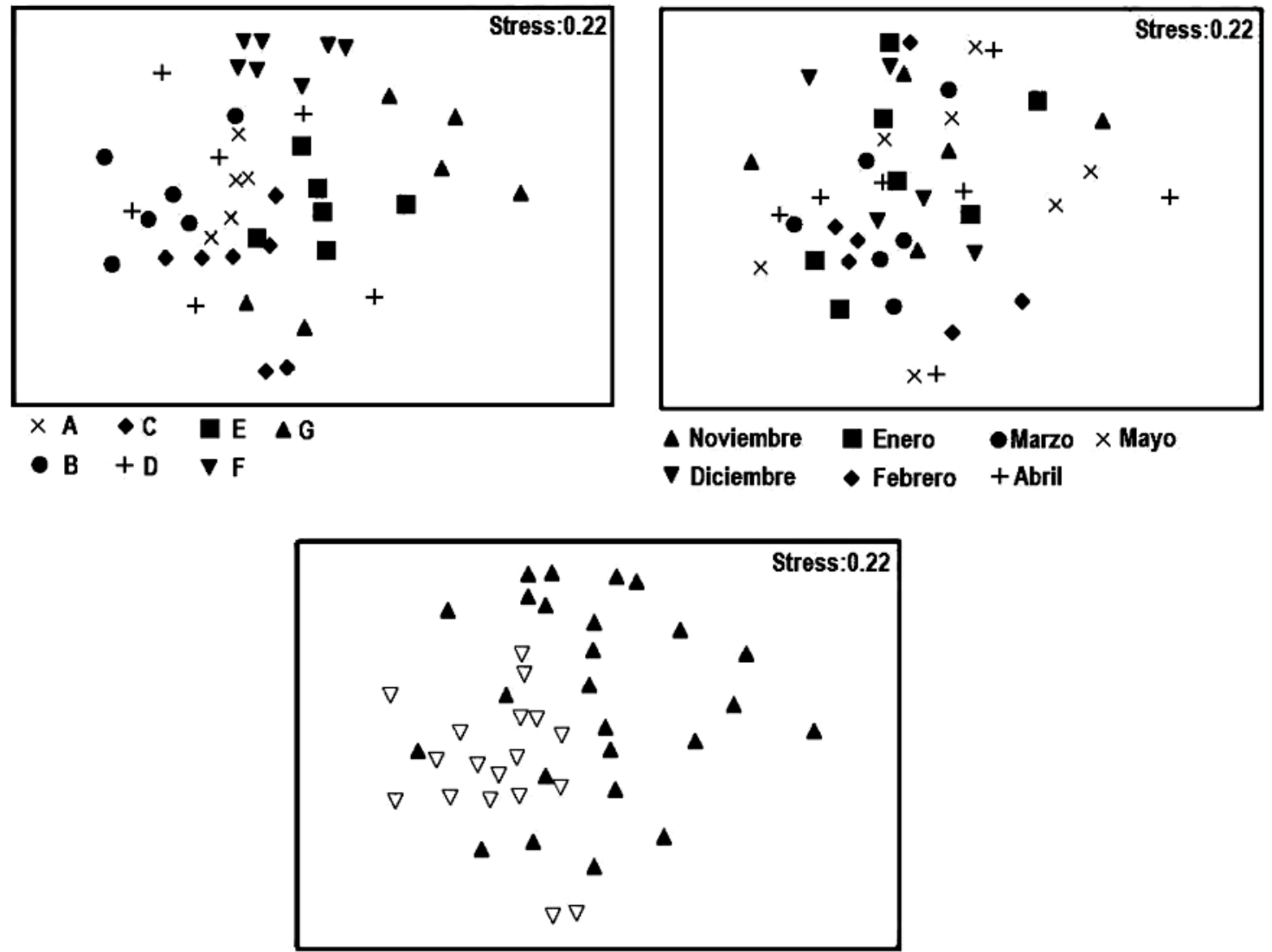

$\nabla$ Sector Uno

$\Delta$ Sector dos

Figura 2. N-MDS mostrando la similitud espacio-temporal de las muestras en cada una de las estaciones de muestreo respecto a la composición y abundancia de las especies de microalgas perifíticas encontradas en el Humedal de Jaboque. 
Tabla 4. Resultados pruebas pareadas dentro del grupo (meses) ANOSIM (2 vías-cruzado) para abundancias de especies.

\begin{tabular}{|c|c|c|c|c|c|c|}
\hline \multirow[t]{2}{*}{ Grupo-meses } & Diciembre & Enero & Febrero & Marzo & Abril & Mayo \\
\hline & \multicolumn{6}{|c|}{ R Global/P-valor } \\
\hline Noviembre & $-0.186 / 0.762$ & $0.131 / 0.24$ & $0.198 / 0.22$ & $0.126 / 0.295$ & $0.294 / 0.083$ & $0.193 / 0.169$ \\
\hline Diciembre & & $-0.167 / 0.84$ & $0.101 / 0.32$ & $0.143 / 0.181$ & $0.284 / 0.066$ & $0.008 / 0.46$ \\
\hline Enero & & & $0.272 / 0.08$ & $0.08 / 0.343$ & $0.069 / 0.343$ & $0.19 / 0.117$ \\
\hline Febrero & & & & $-0.134 / 0.723$ & $-0.014 / 0.554$ & $0.317 / 0.077$ \\
\hline Marzo & & & & & $-0.001 / 0.491$ & $0.226 / 0.14$ \\
\hline Abril & & & & & & $-0.154 / 0.817$ \\
\hline
\end{tabular}

caso, la disimilitud tan alta entre muestras pese a que presentan el mismo número de especies se debe a la diferencia entre su composición y contribución. Las estaciones que corresponden al sector uno son más homogéneas en composición y abundancia que las del sector dos entre la alta variabilidad que igualmente se registra para todas las estaciones en el humedal. Las muestras de la estación $\mathrm{D}$ que corresponde al tramo final de adecuación de canales perimetrales en dirección sur-norte del humedal, son las que presentan mayor heterogeneidad de todas las examinadas caracterizándose además, por exhibir una mayor similitud con las de las estaciones del sector uno como se aprecia en el análisis de ordenación, Figura 2.

Por otra parte, las mayores abundancias (indv/ $/ \mathrm{cm}^{2}$ ) durante todo el estudio se presentan en las estaciones del sector dos, donde el valor máximo encontrado fue para la estación $\mathrm{F}$ (98891 indv/ $\mathrm{cm}^{2}$ ) y la menor abundancia registrada para la estación $\mathrm{B}\left(76 \mathrm{indv} / \mathrm{cm}^{2}\right)$ en el mes de mayo. La heterogeneidad en el sistema en composición y abundancia es muy alta.

En el análisis de ordenación de las muestras el valor de stress obtenido $(0.22,478$ reiteraciones $)$, se encuentra dentro de un intervalo de 0.2-0.3 indicando una no muy buena representación, que puede deberse al elevado número de muestras; al aumentar las dimensiones (3d) el estrés disminuye $(0.16,489$ reiteraciones) siendo útil, pero una mayor dimensionalidad no añade información adicional. En este caso, el análisis de similitudes (ANOSIM) corresponde a lo mostrado en el análisis de ordenación (N-MDS).
Las abundancias y composición (indv/ $\mathrm{cm}^{2}$ ) de las especies encontradas, muestran diferencias estadísticamente significativas entre las estaciones que se encuentran en los sectores uno y dos del humedal (ANOSIM, test global, $\mathrm{R}=0.207, \mathrm{P}<0.05$ ), Tabla 3 . Los valores de $\mathrm{R}$ cercanos a cero indican que existe una mínima segregación de los grupos. A escala temporal las muestras recolectadas no mostraron diferencias estadísticamente significativas entre los meses (ANOSIM, test global, $\mathrm{R}=0.079, \mathrm{P}>0.05$ ). En la prueba pareada entre estos, las abundancias no fueron significativamente diferentes para ninguna de las comparaciones posibles (ANOSIM, P $>0.002$ ), Tabla 4. No obstante, los valores negativos para $\mathrm{R}$ en las pruebas pareadas señalan que existen diferencias dentro de los meses, debido a la variabilidad que existe entre las estaciones de cada sector.

En el dendrograma de asociación Figura 3, a pesar del agrupamiento entre sectores, se muestra que la formación de grupos definidos por similitud entre los valores de abundancia es muy baja del 20 y $50 \%$, correspondiendo en la mayoría de los casos, a las muestras de una determinada estación en los diferentes meses de muestreo.

Las mayores abundancias en cuanto a los meses estudiados pueden estar presentándose en los meses de abril y mayo con promedios de 26007 y $20693 \mathrm{indv} / \mathrm{cm}^{2}$ respectivamente, pero solo debido a algunas estaciones del sector dos para estos meses, no de una forma general para todo el sistema, estos corresponden a la época de 
Tabla 5. Resultados de SIMPER-Contribución de especies a la disimilitud entre las estaciones del sector uno y dos.

\begin{tabular}{|c|c|c|c|c|c|c|}
\hline \multirow{2}{*}{$\begin{array}{l}\text { Promedio de disimilitud } \\
82.49 \% \\
\text { Especies }\end{array}$} & \multirow{2}{*}{$\begin{array}{l}\text { Sector uno } \\
\text { Prom. de } \\
\text { Abundancias } \\
\text { Indv/cm² }\end{array}$} & \multirow{2}{*}{$\begin{array}{l}\text { Sector dos } \\
\text { Prom. } \\
\text { de abundancias } \\
\text { Indv/cm² }\end{array}$} & \multicolumn{4}{|c|}{ Punto de corte: $50 \%$} \\
\hline & & & Av.Diss & Diss/SD & Contrib\% & Cum. \% \\
\hline Nizschia sp & 832 & 1116 & 4.54 & 1.26 & 5.51 & 5.51 \\
\hline Trachelomonas hispida & 1 & 2631 & 4.37 & 0.84 & 5.30 & 10.81 \\
\hline Lepocinclis sp & 117 & 1390 & 4.36 & 1.30 & 5.29 & 16.10 \\
\hline Oscillatoria sp & 70 & 877 & 3.98 & 0.95 & 4.83 & 20.93 \\
\hline Navicula sp & 36 & 720 & 3.38 & 1 & 4.09 & 25.02 \\
\hline Nizschia sp, & 127 & 157 & 3.06 & 0.85 & 3.71 & 28.74 \\
\hline Euglena sp & 16 & 210 & 2.94 & 0.89 & 3.56 & 32.30 \\
\hline Gomphosphaeria sp & 17 & 1996 & 2.73 & 0.48 & 3.31 & 35.61 \\
\hline Pinnularia sp & 57 & 10 & 2.58 & 1 & 3.13 & 38.74 \\
\hline Phacus sp & 12 & 6431 & 2.53 & 0.68 & 3.07 & 41.01 \\
\hline Closterium cornu & 10 & 331 & 2.43 & 0.62 & 2.95 & 44.76 \\
\hline Navicula $\mathbf{S p}_{5}$ & 25 & 25 & 2.33 & 0.85 & 2.82 & 47.58 \\
\hline Nizschia $\mathbf{s p}_{2}$ & 12 & 118 & 2.22 & 0.63 & 2.70 & 50.27 \\
\hline
\end{tabular}

Tabla 6. Resultados de SIMPER-Contribución de especies a la similitud de las estaciones del sector dos.

Promedio de similitud

$18,77 \%$

Especies

Lepocinclis sp

Trachelomonas hispida

Euglena sp

Nitzschia sp

Navicula sp,

Oscillatoria sp

Nitzschia sp,

Gomphosphaeria sp

Phacus sp

Closterium cornu

Phacus curvicauda

Nizschia $\mathbf{s p}_{2}$

Euglena fusca

Merismopedia sp

Chlamydomonas sp

Synedra ulna

Phacus tortus

Navicula $\mathbf{S p}_{4}$

Pinnularia sp
Sector dos

Punto de corte: $\mathbf{9 0 \%}$

Promedio de abundancias

indv/cm ${ }^{2} \quad$ Av.Sim Sim/SD Contrib\% $\quad$ Cum.\%

$\begin{array}{lllll}1389 & 3.21 & 0.72 & 17.10 & 17.10 \\ 2632 & 2.78 & 0.53 & 14.81 & 31.91 \\ 210 & 1.48 & 0.49 & 7.86 & 39.77 \\ 1116 & 1.45 & 0.47 & 7.73 & 47.50 \\ 720 & 1.41 & 0.43 & 7.53 & 55.03 \\ 877 & 1.40 & 0.33 & 7.47 & 62.50 \\ 157 & 0.88 & 0.30 & 4.69 & 67.19 \\ 1996 & 0.67 & 0.19 & 3.56 & 70.75 \\ 6431 & 0.62 & 0.25 & 3.28 & 74.02 \\ 331 & 0.57 & 0.23 & 3.05 & 77.08 \\ 58 & 0.45 & 0.26 & 2.38 & 79.46 \\ 118 & 0.45 & 0.20 & 2.37 & 88.72 \\ 79 & 0.43 & 0.25 & 2.29 & 84.12 \\ 1773 & 0.28 & 0.22 & 1.48 & 85.60 \\ 1157 & 0.21 & 0.18 & 1.15 & 8.674 \\ 167 & 0.19 & 0.17 & 1.03 & 87.77 \\ 501 & 0.18 & 0.17 & 0.95 & 88.72 \\ 27 & 0.18 & 0.13 & 0.94 & 89.66 \\ 10 & 0.18 & 0.17 & 0.93 & 90.60\end{array}$


Tabla 7. Resultados de SIMPER-Contribución de especies a la similitud de las estaciones en el sector uno.

Promedio de similitud

28.72\%

Especies

Nizschia sp

Lepocinclis sp

Oscilatoria sp

Pinnularia sp

Navicula $\mathbf{S p}_{5}$

Navicula $\mathbf{s p}_{2}$

Closterium sp,

Navicula $\mathbf{s p}_{2}$

Navicula sp

Nizschia sp,

Navicula $\mathbf{s p}_{4}$
Sector uno de abundancias indv/cm ${ }^{2}$

832

117

70

57

25

37

11

36

46

126

6
Av.Sim

7.27

6.19

2.65

2.46

1.61

1.21

1.16

1.05

1.02

0.89

0.52
Punto de corte: $\mathbf{9 0 \%}$

Sim/SD Contrib\% Cum. $\%$

$\begin{array}{lll}1.04 & 25.32 & 25.32 \\ 1.06 & 21.55 & 46.87 \\ 0.59 & 9.22 & 56.09 \\ 0.61 & 8.57 & 64.66 \\ 0.46 & 5.61 & 70.27 \\ 0.35 & 4.23 & 74.50 \\ 0.38 & 4.02 & 78.52 \\ 0.32 & 3.67 & 82.19 \\ 0.38 & 3.55 & 85.74 \\ 0.32 & 3.11 & 88.85 \\ 0.25 & 1.82 & 90.67\end{array}$

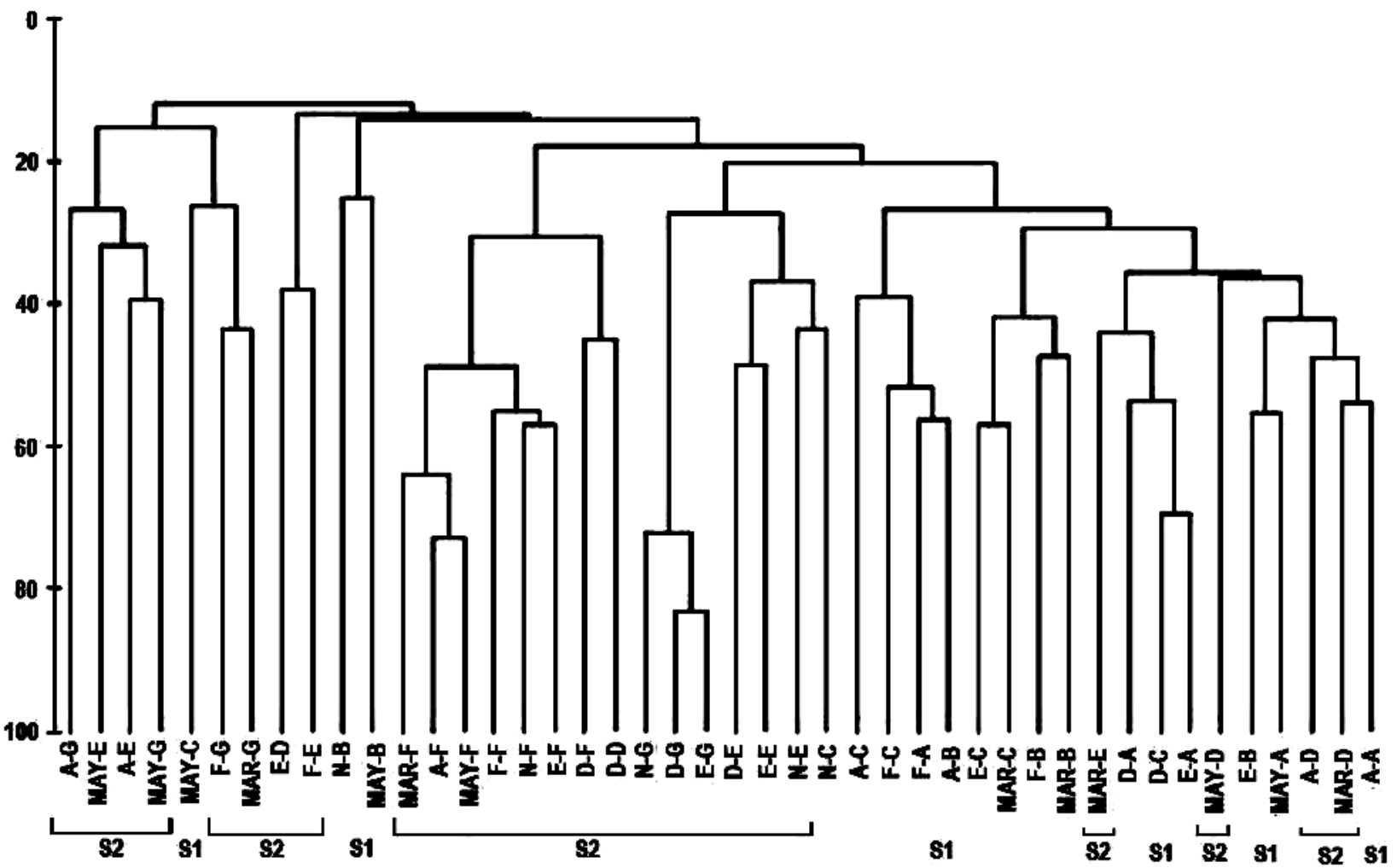

Figura 3. Dendograma de asociación entre las abundancias de las microalgas perifíticas encontradas durante el estudio señalando el agrupamiento entre zonas. La inicial que precede a la estación corresponde al mes de muestreo.

menor cantidad de lluvias. En febrero y marzo meses de La estación que registró las mayores abundancias a lo mayor sequía y, pluviosidad moderada respectivamente, largo de todo el estudio fue la $\mathrm{F}$ (sector dos) con un se registraron las abundancias promedio mas bajas, pero promedio de $52477 \mathrm{indv} / \mathrm{cm}^{2}$ y para la cuál el grupo más este patrón se presenta solo para las estaciones A, E y G. representativo fueron las euglenófitas que explica que se 
Tabla 8. Valores de diversidad (Índice de Shannon-Weaver) de microalgas perifíticas para cada una de las estaciones durante todo el estudio en el Humedal de Jaboque.

$\begin{array}{lllllllll} & \text { A } & \text { B } & \text { C } & \text { D } & \text { E } & \text { F } & \text { G } & \begin{array}{l}\text { Valor } \\ \text { Promedio }\end{array} \\ \text { Noviembre } & * & 0.89 & 1.51 & * & 1.34 & 1.55 & 0.88 & 1.23 \\ \text { Diciembre } & 1.69 & & 1.74 & 0.42 & 1.57 & 1.50 & 0.91 & 1.30 \\ \text { Enero } & 1.92 & 1.23 & 1.08 & 0.77 & 1.75 & 0.75 & 1.02 & 1.22 \\ \text { Febrero } & 1.73 & 1.46 & 1.64 & 0.83 & * & 0.86 & 1.61 & 1.36 \\ \text { Marzo } & * & 1.59 & 1.23 & 2.25 & 1.72 & 2.56 & 1.01 & 1.72 \\ \text { Abril } & 1.82 & 1.35 & 1.64 & 2.22 & 1.97 & 1.23 & 0.17 & 1.49 \\ \text { Mayo } & 0.85 & 0.95 & 1.09 & 1.62 & 1.06 & 1.94 & 0.82 & 1.19 \\ \text { Valor } & & & & & & & & \\ \text { Promedio } & 1.60 & 1.25 & 1.42 & 1.35 & 1.57 & 1.48 & 0.92 & \end{array}$

\section{Grupos \\ Estaciones \\ Meses \\ ${ }^{*}$ P-valor $=0.05$}

Estadístico $\mathrm{F}$

1.06

1.11
P-valor

0.4031

0.3740 distingan como grupo más abundante. La estación con la menor abundancia promedio fue la $\mathrm{C}$ (sector uno) con $516 \mathrm{indv} / \mathrm{cm}^{2}$.

En relación con las diferencias encontradas entre las estaciones que pertenecen al sector uno y dos, las especies que contribuyen al $82.49 \%$ de disimilitud son las mismas que contribuyen a la baja similitud entre las estaciones que corresponden a cada uno de los sectores y a la marcada diferencia entre las abundancias. Es decir, a pesar de presentarse mayor homogeneidad en la composición de la estaciones del sector uno, la heterogeneidad en el sistema es muy alta, Tabla 5. Las especies con un $50 \%$ de contribución al bajo promedio de similitud $(18,77 \%)$ entre las estaciones del sector dos son: Lepocinclis sp, Trachelomonas hispida (Perty) Stein emend., Euglena $s p_{5}$, Nizschia sp y Navicula $s p_{1}$, Tabla 6. Para las estaciones del sector uno con un promedio de similitud de $28,72 \%$ figuran Nizschia $s p$, Lepocinclis sp., y Oscillatoria sp, Tabla 7.

Las especies más abundantes, aunque en diferentes proporciones para todas las estaciones y que excedieron los $1000 \mathrm{indv} / \mathrm{cm}^{2}$ en el sector dos fueron: Phacus sp que fue característica y una de las especies dominantes en la estación F, Trachelomonas hispida, Gomphosphaeria sp, Merismopedia sp, Lepocinclis sp y Nizschia sp, Tabla 5. Para las estaciones del sector uno se puede observar que las abundancias promedio de las especies encontradas estuvieron muy por debajo de las halladas en las estaciones del sector dos, las más abundantes por encima de $100 \mathrm{indv} / \mathrm{cm}^{2}$ fueron: Nizschia $s p$, Lepocinclis $s p$ y Nizschia $s p_{l}$, Tabla 7.

La asociación entre especies en cada una de la estaciones es muy baja, por la dominancia o codominancia de algunas, pero las que permiten que exista alguna similitud entre las estaciones que pertenecen a cada uno de los sectores se pueden asignar como especies indicadoras o características dentro de estos, con mejor adaptación a las condiciones análogas que puedan estar ocasionándose, en este caso, para un conjunto de estaciones o sector del humedal pudiendo identificar más fácilmente las variables que están determinando su estado.

De igual forma, las especies que se mantuvieron mas o menos constantes a escala temporal para cada una de las estaciones fueron: Lepocinclis $s p(\mathrm{~A}, \mathrm{~B}$, D y F), Navicula $s p_{5}(\mathrm{~A})$, Navicula $s p_{4}(\mathrm{~A}, \mathrm{~B}, \mathrm{C})$ 
Nizschia sp (A), Synedra ulna (A, B, D y F), Gomphosphaeria sp (C), Navicula sp. (C y E), Phacus curvicauda Swirenko (D), Trachelomonas hispida (E Y G), Euglena sp (E y F), Choroomona sp (E), Phacus sp.(F) Phacus longicauda (Ehrenb.) Dujard., (F), Euglena fusca (Klebs) Lemmermann (F) Chlamydomonas sp (F), Navicula $s p_{1}(\mathrm{~F}) \mathrm{y}$ Oscillatoria $s p(\mathrm{G})$. Aunque se presentaron especies comunes entre las estaciones de ambos sectores, la disimilitud tan alta entre muestras es debida a las diferencias en los valores de abundancia, en general, la preponderancia fue la presencia de especies raras.

La diversidad hallada para todo el sistema durante el periodo de estudio osciló alrededor de $1.36 \pm 0.50$ bits de información. Se encontró un valor mínimo de 0.17 para la estación $\mathrm{G}$ en Abril y un valor máximo de 2.56 para la estación $\mathrm{F}$ en Marzo. Los valores promedio más altos en diversidad se registraron en Marzo con un valor de 1.72 y en Abril de 1.49. Las estaciones con la mayor y menor diversidad promedio fueron la A y G, respectivamente, Tabla 8.

Los valores de diversidad encontrados, no mostraron diferencias estadísticamente significativas entre todas las estaciones (ANOVA, $\mathrm{P}>0.05$ ) y entre los meses de muestreo (ANOVA, P >0.05), Tabla 9. La diversidad se mantiene baja y fluctúa con la misma intensidad durante los meses estudiados para cada una de las estaciones.

Las variables fisicoquímicas del agua no mostraron diferencias estadísticamente significativas a escala espacio-temporal (Kruskal-Wallis, P-valor $=0.9999$ $\mathrm{P}>0.05$ ). La correlación entre los datos abióticos y bióticos efectuada a partir del procedimiento BIOENV indica de forma general una correspondencia no muy alta entre las variables fisicoquímicas de la columna de agua y el comportamiento de las microalgas perifiticas.

El coeficiente de correlación más alto entre las variables analizadas individualmente fue el obtenido para la DT (ñù =0.349). Otras variables que revelaron alguna relación fueron AT (ñù $=0.261), C$ (ñù $=0.180$ ), $\mathrm{pH}($ ñù $=0.124)$, NT (ñù $=0.115)$, NT (ñù $=0.097) \mathrm{y}$
$\mathrm{T}($ ñù $=0.051)$. La combinación de variables que mejor explica el comportamiento de los datos biológicos fue la conformada por las variables DT, NT y $\mathrm{pH}$ con un coeficiente de Correlación de Spearman de 0.378.

\section{Sucesión}

Durante el estudio del proceso de colonización de las microalgas perifíticas se registraron 50 especies. La representatividad de acuerdo al número total de especies encontradas fue la siguiente: diatomeas con el $38 \%$, seguido de las euglenófitas con $32 \%$, clorófitas y cianófitas con un $14 \%$ y por último las crisófitas con un 2\%. En términos de densidad, el grupo más abundante fue nuevamente el de las euglenófitas con un $58.86 \%$ del total de individuos encontrados, seguido de las diatomeas con un $21.13 \%$, cianófitas con un $11.32 \%$, clorófitas con el $8.65 \%$ y por último las crisófitas con el $0.04 \%$ restante.

La estación $\mathrm{F}$ durante el proceso de colonización registró el valor promedio máximo hasta la sexta semana de exposición de los sustratos de $40.495 \mathrm{indv} /$ $\mathrm{cm}^{2}$ y la estación $\mathrm{B}$ la más baja abundancia con un valor promedio de $6 \mathrm{indv} / \mathrm{cm}^{2}$. Estos resultados hacen más notoria la diferencia en cuanto a las densidades encontradas en las estaciones que corresponden al sector uno y dos del humedal.

En términos de abundancia el proceso de colonización de las microalgas perifíticas mostró para todas las estaciones un comportamiento similar en cuanto al ciclo de crecimiento y decrecimiento en el número de individuos durante tres semanas. Sin embargo, difieren temporalmente y fueron más evidentes para las estaciones del sector dos, donde se registraron los valores más altos. Este ciclo comienza en la tercera semana para las estaciones G, F, D, B y A, Figura 4: g, f, d, b y a. Para la estación E se inicia a la segunda semana, con un posterior decrecimiento hasta la sexta y última semana de exposición de los sustratos, Figura 4 e.

La estación $\mathrm{C}$ exhibe la misma tendencia a la estación anterior excepto que en el tiempo 

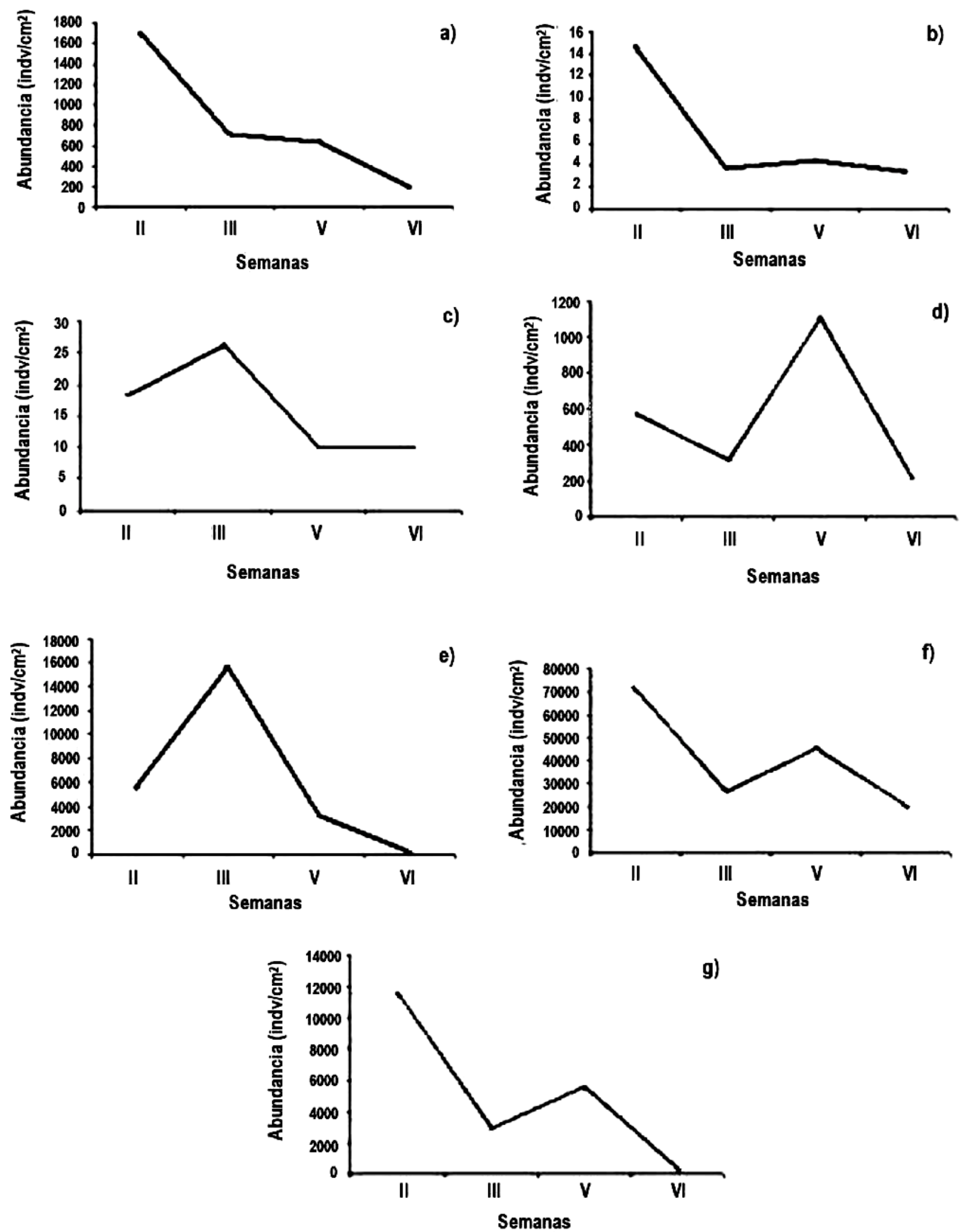

Figura 4. Variación de los valores de abundancia (indv/ $\mathrm{cm}^{2}$ ) a la II, III, V y VI semana de exposición de los sustratos artificiales en cada una de las estaciones de muestreo .Estaciones: A (a), B (b), C (c), D (d), E (e), F (f) y G (g). 

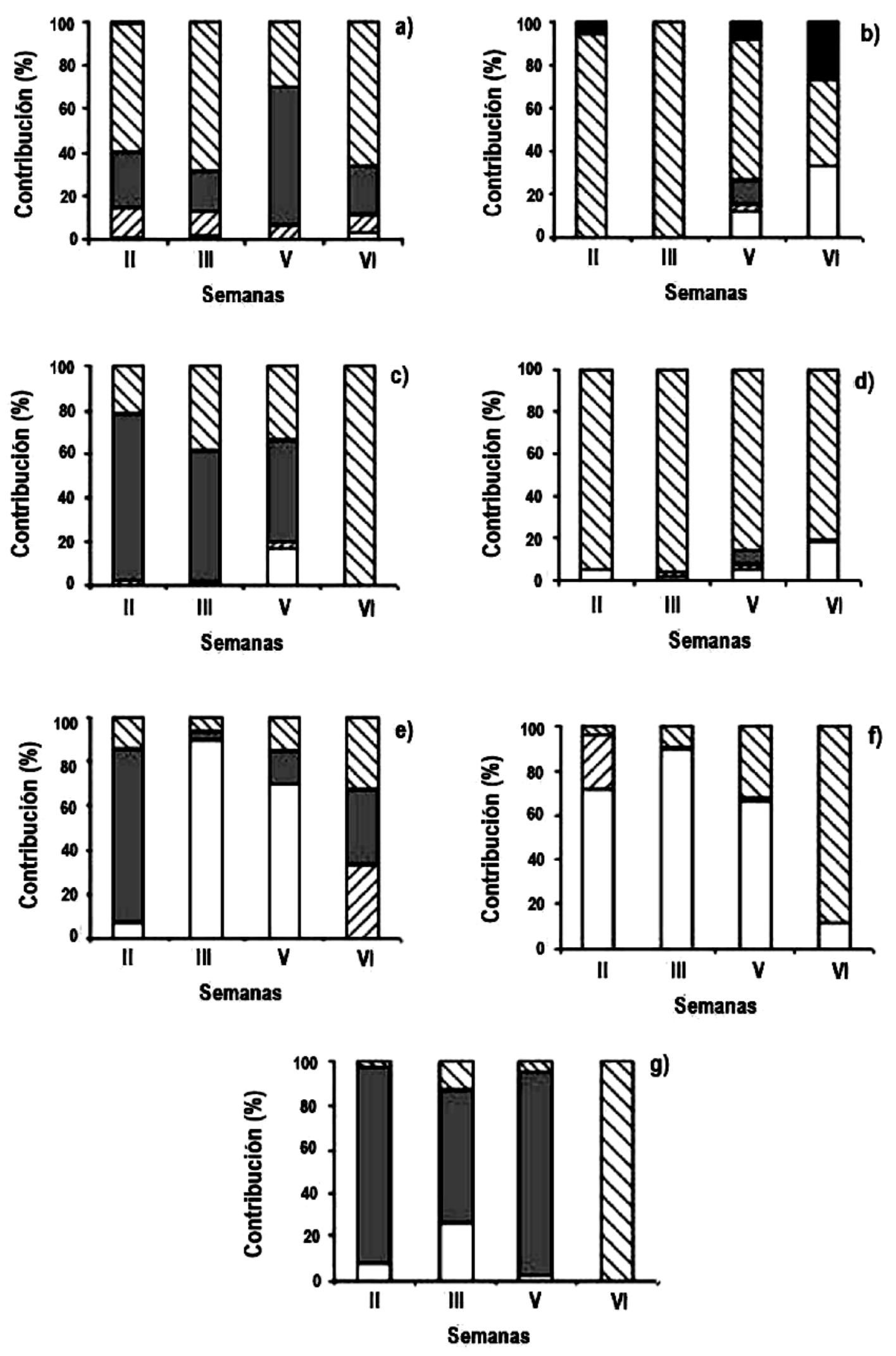

crisófitas $\quad$ diatomeas $\square$ cianófitas $\square$ clorófitas $\square$ euglenófitas

Figura 5. Porcentajes de contribución de cada uno de los grupos de microalgas encontrados a la II, III, V y VI semana de exposición de los sustratos artificiales en cada una de las estaciones de muestreo. Estaciones: A (a,), B (b), C (c), D (d), E (e), F (f) y G (g). 
transcurrido entre la quinta y sexta semana los valores de abundancia se mantienen, Figura 4 c. La contribución y sucesión de los grupos de microalgas durante el periodo de colonización fue muy diferente para cada una de las estaciones.

En la estación A para la segunda semana de exposición de los sustratos, se evidenció que los grupos con mayores abundancias en la etapa de colonización eran las cianófitas y las diatomeas, estas últimas son las que predominaban en la segunda, tercera y sexta semana, Figura 5a. Para la estación B las diatomeas y las crisófitas fueron las más abundantes en la segunda semana, las primeras dominaron también en la tercera y quinta semana cuando empiezan a decrecer en la última semana de exposición de los sustratos y aparecen casi en la misma proporción a las euglenófitas, Figura 5b. Para finalizar con las estaciones que corresponden al sector uno del humedal, en la $\mathrm{C}$, las microalgas más representativas hasta la quinta semana fueron las cianófitas, para dar paso y dominar posteriormente las diatomeas en la sexta semana, Figura 5c.

Respecto a las estaciones que pertenecen al sector dos en la $\mathrm{D}$, el grupo de microalgas que coloniza con mayores abundancias y se mantiene hasta la última semana son las diatomeas, Figura 5d. En las estaciones E y G abunda el grupo de la cianófitas en la segunda semana decrece y predominan las euglenófitas y cianófitas respectivamente (tercera semana), finalizando la estación E con igual proporción de clorófitas, cianófitas y diatomeas, con un predominio total de estas últimas para la estación G, Figuras 5e y $5 \mathrm{~g}$.

En la estación $\mathrm{F}$ el proceso de sucesión difiere notablemente respecto a la segunda semana de exposición de los sustratos, dominando las euglenófitas como se ha observado a lo largo de todo el estudio para esta estación hasta la quinta semana, cuando decrecen y se da un comportamiento inverso de las diatomeas hasta la sexta y última semana cuando son las más abundantes, Figura 5f. Las diatomeas están presentes en todas las estaciones en la segunda semana, y si bien decrecen o aumentan durante la tercera y quinta semana igualmente se mantienen en el último periodo de exposición de los sustratos.

Los valores de diversidad obtenidos durante el periodo de exposición no exceden el valor de 2.5 , la diversidad más alta fue de 2.23 para la estación E en la quinta semana, y la diversidad más baja registrada durante el estudio de colonización fue de 0.47 en la estación G. Las estaciones que mostraron mayores diversidades durante todo el periodo fueron la $\mathrm{F}$ y la $\mathrm{A}$, con valores promedio de 1.82 y 1.81 respectivamente. Finalmente las semanas donde se hallaron mayores diversidades fueron la segunda y quinta semana con valores promedio de 1.47 y 1.49 , respectivamente.

\section{Discusión}

\section{Composición y abundancia}

Las algas perifíticas representan una de las comunidades con mayor variabilidad espacial en términos de biomasa y composición (30) y es frecuente encontrar que ninguna de la especies mantiene a lo largo del año un tamaño considerable de su población (31). Para el humedal de Jaboque se evidenció una alta heterogeneidad espacial, producto de sus características tróficas y factores físicos que afectan al sistema. El grupo de las diatomeas en mayor o menor proporción está presente a lo largo de todo el humedal, esto indica el proceso de eutrofización por el que atraviesa el sistema (32).

Las variables fisicoquímicas del agua no mostraron diferencias estadísticamente significativas ni espacial ni temporalmente, esto ayuda a interpretar, en parte, la correlación tan baja obtenida en el BIOENV. La correspondencia más alta alcanzada entre los datos abióticos y bióticos fue para la combinación de variables de dureza total $(\mathrm{mg} / \mathrm{L})$, nitrógeno total $(\mathrm{mg} / \mathrm{L})$ y $\mathrm{pH}$ que según el coeficiente de Spearman explican aproximadamente un $38 \%$ de la elevada variabilidad espacial en la estructura de la comunidad perifítica, lo que indica que las condiciones en su mayoría tróficas 
son muy similares para todo el sistema, y que aunque inciden de forma parcial, existen otro tipo de variables que no fueron incluidas en el análisis y que explicarían el comportamiento de la comunidad. La incidencia de luz en la columna de agua y la hidrodinámica del sistema no fueron medidas directamente en este estudio. Sin embargo, durante el muestreo se observó que podrían estar determinando la variabilidad en los resultados obtenidos.

Las estaciones que pertenecen al sector uno, por ejemplo, se encuentran caracterizadas en términos de composición y abundancia por el grupo de las diatomeas. Teniendo en cuenta que las condiciones tróficas no muestran diferencias significativas espacio-temporalmente sólo de forma particular para algunas estaciones, el ambiente físico y en menor medida la disponibilidad de los nutrientes determinan los bajos valores de abundancia encontrados, así como, la representatividad de este grupo en esta zona.

El valor promedio de abundancia en este sector, finalmente fue de $774 \mathrm{indv} / \mathrm{cm}^{2}$, muy inferior para las condiciones tróficas que se presentan de forma general para todo el sistema en comparación con otros estudios. Donato et al. (7), encontraron para el sistema oligotrófico de la Laguna de Chingaza, valores de $400 \mathrm{indv} / \mathrm{cm}^{2}$ en las estaciones de menor abundancia y valores superiores a $1800 \mathrm{indv} / \mathrm{cm}^{2}$ en las estaciones de mayor abundancia de microalgas perifíticas. Roldán (5), registra con base en un estudio realizado por Moreno (1988), abundancias de $2989 \mathrm{indv} / \mathrm{cm}^{2}$ durante un periodo más largo de exposición de los sustratos (tres semanas) para un sistema oligotrófico.

Por tal razón, los valores tan bajos hallados en este sector pueden ser debidos a que para el hábitat bentónico actúan otros factores como los físicos e hidrológicos (7, 31, 33-35). En el humedal, la reducción del espejo de agua debido al crecimiento de macrófitas acuáticas es muy alta y difiere espacialmente, en consecuencia también la cantidad de luz disponible.

En otros estudios se ha observado que se producen cambios en la estructura de las comunidades de perifíton a medida que se pasa de zonas soleadas a zonas de sombra (5). Entre las estaciones estudiadas las que mayor cobertura de macrófitas acuáticas presentaron durante el estudio con excepción de la estación A, la cual está más influenciada por vegetación arbustiva, fueron las del sector uno, pudiendo explicar las bajas abundancias y la composición de la comunidad, convirtiéndose la luz en uno de los factores limitantes mas concluyentes.

Las macrófitas dejan fuera de competencia por la luz al fitoplancton y al perifíton, por que forman densas capas que reducen o eliminan la entrada de luz a la columna de agua $(36,37)$. En este sentido también puede estarse presentando una competencia entre macrófitas, fitoplancton y perifíton por los nutrientes, minimizando la disponibilidad de estos $(36,38,39)$ a pesar de encontrarse presentes como se mencionó anteriormente. La abundancia y biomasa de macrófitas acuáticas determinan la distribución y abundancia de las algas adheridas a los sustratos (37).

Es importante anotar que la reducción del espejo de agua se incrementó durante el estudio para algunas de las estaciones y que además, se constituyó como una variable entre todas las estaciones muestreadas a lo largo del tiempo al igual que las fluctuaciones en el nivel y flujo del agua. Las diatomeas por ejemplo, aparentemente no son tan afectadas por las variaciones de luz (31), motivo por el cuál se encuentran presentes en todo el sistema y con mayor representatividad en el sector uno, donde el espejo de agua se encuentra cubierto por una densa capa de macrófitas acuáticas.

Por otro lado, el perifíton se desarrolla mejor en sustratos que le ofrezcan estabilidad y donde la acción de las corrientes es mínima (5). Este puede ser el caso del sector dos, donde a pesar de las fluctuaciones evidenciadas para todo el sistema en la columna de agua producto de las condiciones hidrológicas, la velocidad e intensidad del flujo es imperceptible.

El flujo tiene una gran influencia sobre la densidad, cuando es débil las abundancias son mayores y 
viceversa (33). La fragmentación y adecuación de canales perimetrales en el sector dos ha causado un mayor estancamiento de las aguas. En relación a esto, las diatomeas desarrollan estrategias que les permite desarrollarse en condiciones inversas como se presentan en la zona menos intervenida.

En condiciones de sequía o pluviosidad moderada en el sector uno se aprecia como el flujo de agua con una mayor o menor intensidad se dirige hacia el río Bogotá, pero, en época de lluvias cuando se incrementa su caudal las aguas desembocan en el humedal provocando un cambio en la dirección e intensidad del flujo de agua en el sector norte (sector uno).

La prevalencia del grupo de las diatomeas a lo largo de todo el sistema, pese, a las diferencias en la disponibilidad de luz e hidrodinámica entre los sectores uno y dos es debida, a que se pueden encontrar en ambientes con sustratos burdos, fuertes gradientes y cambios, una extensa cobertura vegetal y baja conductividad, hasta ambientes con buenos sustratos, pequeños gradientes, gran conductancia, estables y poca cobertura vegetal (40). Cuando las áreas colonizables son más reducidas las especies son típicamente perifíticas y las abundancias son más bajas (7) como sucede en el sector uno.

En el sector dos; sin embargo, se presentan especies que normalmente no son propiamente perifíticas, como es el caso de las euglenófitas que se distribuyen entre el plancton y el bentos (41). Este grupo de microalgas bajo condiciones favorables puede desarrollarse en exceso (31), por lo cual, eventualmente pueden ocupar otros nichos (42), como se observó en la estación $\mathrm{F}$ y de forma general para el sector dos. En esta zona, la afluencia de materia orgánica alóctona al sistema a partir de las conexiones erradas de los barrios aledaños puede favorecer el crecimiento de este grupo (32). En aguas enriquecidas con sustancias orgánicas aumentan proporcionalmente la cantidad de cianófitas y de flagelados (31).

La ausencia de corrientes en el sector dos, como se mencionó anteriormente, y menor nivel de la columna de agua podrían estar contribuyendo a la mayor representatividad del grupo de las euglenófitas en esta zona. Las euglenófitas son más frecuentes en aguas estancadas y someras (43).

Así mismo, los valores de abundancia obtenidos son bastante altos si se tiene en cuenta el estado trófico del humedal (29). La reoxigenación en este sector $(33.6 \%)$ es mayor que en la zona menos intervenida (5.5\%) debido a la estación $\mathrm{F}$ donde se presenta un porcentaje de saturación de oxigeno promedio de 119.75 , en este sentido, la composición y crecimiento algal reflejado en los valores de densidad obtenidos interviene favorablemente.

Las euglenófitas tienen una importancia ecológica primordial en aguas ricas en nutrientes y materia orgánica puesto que aportan oxigeno evitando condiciones anóxicas en ambientes con estas características permitiendo a su vez el crecimiento de bacterias aeróbicas que contribuyen a la depuración de las aguas (43).

En la estación F (sector dos) durante la época de mayor sequía se evidenció el aporte de organismos de otras comunidades según Donato et al. (7) esto ocurre accidentalmente o para completar parte de su ciclo de vida. En las estación F los sustratos artificiales fueron ubicados en el limite entre el humedal y el canal perimetral donde la cantidad de sustratos disponibles se ha acrecentado con la introducción de elementos ajenos producto de la actividad antrópica; sumado a esto, la disminución de la columna de agua dadas las condiciones pluviométricas puede influir.

Adicionalmente, el aporte de materia orgánica por la afluencia directa de las aguas residuales conducidas por el sistema de canalización cuando este se colmata, puede estar siendo significativa en el sector dos con una mayor incidencia para la estación F manifestándose en los altos valores de abundancia obtenidos y la composición de la comunidad perifítica.

A escala temporal los valores de abundancia no mostraron patrones definidos, la inestabilidad mensual evidenciada para todo el sistema puede ser consecuencia de la alteración en la hidrodinámica 
producto de la fragmentación del humedal desencadenando el comportamiento aislado en cada una de las estaciones, por tal razón, no se encontraron diferencias estadísticamente significativas entre los meses de muestreo, pero si dentro de estos.

En ambientes lénticos, con alta incidencia antrópica, se espera que en periodos lluviosos la carga de nutrientes aumente, pero sólo hasta la época seca se produzca un mayor crecimiento de algas debido a la descargas de origen antrópico, mayor concentración de nutrientes y menor turbiedad (12). En contraposición a esto, para el humedal de Jaboque con una estacionalidad tan marcada respecto al régimen de pluviosidad, las menores abundancias coinciden con los meses de febrero y marzo que corresponden al final de la época seca mayor y comienzos de la época lluviosa menor, respectivamente.

Los meses de mayor abundancia para todo el sistema se presentaron en el periodo con menor lluvia. Esto corrobora aun más la inestabilidad hidrodinámica del sistema que no permite que exista un flujo normal del agua y que se evidencien patrones estacionales definidos. Sin embargo, el grupo de las euglenófitas presentó mayores abundancias en la época de mayor sequía para la estación $\mathrm{F}$, posiblemente debido al menor flujo y disminución en la columna de agua que permitieron una mayor concentración de nutrientes.

La diversidad para el sistema es extremadamente baja, hallándose valores inferiores a 2.5 y en algunos casos inferiores a 0.5 (bits de información). En relación al fitoplancton de aguas dulces, se ha encontrado que una diversidad muy por debajo de 1 es característica de los lagos muy eutróficos, hasta un máximo de 5 en lagos oligotróficos y distróficos (44). Los valores de diversidad oscilaron durante el periodo de estudio para cada una de las estaciones de muestreo conforme a lo hallado en los datos de composición y abundancia. Este comportamiento es característico de sistemas eutróficos e inestables (5).

El predominio de especies raras y dominancia de unas pocas, incrementan la disimilitud entre estaciones, además de tener una correlación negativa con la diversidad, propia de ambientes con poca estabilidad (44). En otros estudios se ha observado que la riqueza taxonómica también se puede ver afectada por la fluctuación en los niveles y flujo del agua (45), la estabilidad hidrodinámica puede favorecer un diversidad alta (46). Cuando existe una alta intervención antrópica las áreas expuestas a esta, muestran variaciones definidas en los valores de abundancia de especies y estructura de la comunidad perifítica (7) promoviendo la aparición de nuevas especies y al mismo tiempo la sustitución de otras (45), como se ha observado para cada una de las estaciones y como consecuencia en los valores de diversidad.

Respecto a los niveles de polución, Roldán (5) realiza una correlación entre los valores de diversidad (H') y el estado de contaminación de las aguas, presentándose aguas muy contaminadas en sistemas con diversidades entre 0.0-0.5 y medianamente contaminadas entre 0.5 y 3.0 , correspondiendo estas categorías a los bajos valores de diversidad encontrados en el humedal.

\section{Sucesión}

En cuanto a los procesos de colonización observados, excepto para la estación $\mathrm{F}$, los grupos más abundantes o que se encuentran siempre presentes en la segunda semana de exposición de los sustratos fueron las cianófitas y las diatomeas. Al llegar la sexta semana, estas últimas son las que dominan en abundancia pudiendo ser las primeras en establecerse $(7,44)$.

Moreira (1988) en un estudio realizado para evaluar la productividad en un embalse y utilizando como sustratos artificiales el polietileno, encontró que las clorófitas, cianófitas y diatomeas fueron los grupos predominantes correspondiendo a un mayor porcentaje de las diatomeas (5). Las clorófitas requieren una buena cantidad de luz para su desarrollo (5) y en este caso, este es un factor limitante; por esto, no fueron muy representativas en la mayoría de estaciones, pero si aparecen con las euglenófitas como las más 
abundantes para la estación $\mathrm{F}$, donde el cuerpo de agua se mantuvo despejado de vegetación emergente durante todo el estudio favoreciendo la entrada de luz y como consecuencia el crecimiento de la comunidad perifítica, además de la entrada adicional de materia orgánica alóctona como se discutió inicialmente.

Respecto a los valores de abundancia encontrados para las estaciones G, F, B y A, los más altos se presentaron durante la segunda semana de exposición de los sustratos, a diferencia de las estaciones restantes, donde los mayores valores de abundancia se registraron en la tercera semana para la estaciones $\mathrm{C}$ y E y quinta semana para la estación D. Los valores máximos podrían estar marcando la etapa final de un ciclo de sucesión, comenzando con anterioridad para las estaciones $\mathrm{G}, \mathrm{F}, \mathrm{B}$ y A, seguido de C y E y por último para la estación $\mathrm{D}$.

Las estaciones ubicadas en las zonas norte y sur del humedal estarían experimentando ciclos de sucesión más rápidos a diferencia de la estación $\mathrm{D}$ que muestra un proceso de colonización más lento que podría ser debido a una mayor inestabilidad en el sistema que se aprecia en la heterogeneidad más alta obtenida entre todas las muestras.

El crecimiento y decrecimiento de los individuos se ocasiona durante un periodo de tres semanas en todas las estaciones independientemente de la semana en que ocurra, esto puede de ser debido a la misma área de colonización expuesta y el tipo de sustrato. El decrecimiento sucede cuando el espacio colonizable disminuye por efecto de la densidad poblacional, actuando también como regulador de la diversidad (7) para disminuir abruptamente por competencia por la luz, nutrientes u otras sustancias (44) y comenzar un nuevo ciclo.

Los valores de diversidad no se mantuvieron constantes durante el periodo de exposición de los sustratos, esto se debe a que resultan de la compensación de variaciones ambientales inversas (41), llegan muchas microalgas diferentes pero solo las mejor adaptadas a las características fisicoquímicas son las que prosperan
(13), cada especie tiene un rango de tolerancia ambiental y preferencias (24). En este caso, de forma general las más adaptadas a las condiciones dadas en el humedal son las diatomeas. Para la mayoría de las estaciones los valores máximos de diversidad corresponden a las abundancias más altas registradas. Según Biggs y Smith (46) en las etapas tempranas de colonización la diversidad es más alta declinando a medida que progresa la sucesión $(47,44)$ del mismo modo que la abundancia. Esto no sucede en las estaciones en la que la dominancia y codominancia de algunas especies es más fuerte como ocurre para las estaciones del sector dos debido a que las condiciones son mucho más favorables para unas especies que para otras.

Por lo anterior se puede concluir que el humedal de Jaboque se encuentra en un proceso de eutrofización, donde la entrada de materia orgánica alóctona, evidenciada por la composición y abundancia de la comunidad perifítica, es más elevada en la zona de mayor urbanización del humedal, en parte, por las conexiones erradas que provienen de los barrios que colindan con el sistema y conducen las aguas servidas hacia este sector. En este sentido, es indispensable identificar estas conexiones debido a que están ingresando las aguas residuales sin previo tratamiento al humedal, siendo perjudiciales en términos ecológicos y sanitarios.

La heterogeneidad en composición y abundancia de microalgas perifíticas es muy alta en todo el humedal debido a la interacción de las condiciones tróficas y físicas que están estructurando la comunidad. La incidencia de luz en la columna de agua y condiciones hidrológicas en función de la hidrodinámica del sistema están determinando el comportamiento de la comunidad perifítica. En este sentido, la fragmentación del sector sur oriental del humedal como consecuencia de la urbanización en el área y el crecimiento anómalo de macrófitas acuáticas están causando la mayor inestabilidad que se ha visto reflejada en la variabilidad de la composición, abundancia, diversidad y procesos de conolización de microalgas perifíticas. 
NOVA - PUBLICACIÓN CIENTÍFICA - ISSN:1794-2470 VOL.4 No. 6 JUNIO - DICIEMBRE DE 2006:1-114

\section{Agradecimientos}

Este estudio fue financiado por la Universidad

Colegio Mayor de Cundinamarca y por el convenio Instituto de Ciencias Naturales/Universidad Nacional de Colombia -Empresa de Acueducto y Alcantarillado de Bogotá, a estas instituciones y a Gerardo Naundorf de la Universidad del Cauca nuestros mas sinceros agradecimientos.

\section{Referencias}

1. Namihira-S P, Barrera-E G, Márquez-G A. Contaminación por bacterias fecales en el Lago Huayamilpas, México D.F. Hidrobiológica 2002; 12 (2): 129- 136.

2. HGA, DAMA. Estado actual de cinco humedales localizados en Santa Fe de Bogotá. Capitulo 4, Volumen II. En: Estudio del estado actual y situación jurídica de cinco humedales del Distrito Capital y la proyección de escenarios a mediano plazo de los humedales contenidos dentro del Acuerdo 19/94. Hidrogeología y Geotecnia Ambiental Ltda. / Departamento Técnico Administrativo del Medio Ambiente. Santa Fe de Bogotá, D. C. Colombia 1999.

3. Naranjo L.G, Andrade G, Ponce de León E. Humedales interiores de Colombia: Bases técnicas para su conservación y uso sostenible. Instituto de Investigación de Recursos Biológicos Alexander Von Humboldt, Ministerio del Medio Ambiente, Bogotá, Colombia 1999.

4. PNHDC. Política de Humedales del Distrito Capital de Bogotá. Departamento Técnico Administrativo del Medio Ambiente (DAMA) Bogotá-Colombia 2004.

5. Roldán G. Fundamentos de limnología neotropical. Editorial Universidad de Antioquia. Medellín-Colombia 1992; 529 p.

6. Andreu E, Camacho A. Recomendaciones para la toma de muestras de agua, biota y sedimentos en humedales Ramsar. Ministerio del Medio Ambiente. Dirección General de Conservación de la Naturaleza. Secretaria General del Medio Ambiente. Madrid.España; 2002. 226 p.

7. Donato J.Ch, González L.E, Rodríguez C.L. Ecología de dos sistemas acuáticos de páramo. Academia Colombiana de Ciencias Exactas, Físicas y Naturales, Colección Jorge Álvarez Lleras No.9.Bogota, D.C Colombia 1996; 168 p.

8. Naundorf G. Las comunidades microbianas, fitoplanctònicas y perifiticas en ecosistemas acuáticos. Universidad del Cauca. Material del Curso Biota Acuática I. Maestría en Recursos Hídricos Continentales. Popayán, Colombia 2002.

9. Henry J, Fisher S. Spatial segregation of periphyton communities in desert streams: causes and consequences for $\mathrm{N}$ cycling. Journal of the American Benthologycal Society 2003; 22(4): 511-527.

10. Meyer J. Grilla de trabajo. Investigación aplicada en restauración en el Humedal de Jaboque, Bogotá-Colombia 2004.

11. Greenberg A.E, Clesceri L.S, Eaton A.D. (eds). Standard methods: for the examination of water and wastewater. 18th. Ed. American Public Health Association -Washington 1992; 1270p.

12. Ramírez A, Viña G. Limnología Colombiana, aportes a su conocimiento. Bogotá. Colombia. Fundación Universidad Jorge Tadeo Lozano. 1998; 293p.

13. Pinilla G, Guillot G. Patrones de distribución del fitoplancton en reservorios de aguas lluvias en un altiplano de los andes colombianos. Rev. Geotrópica 1999; 4: 39-47.

14. Biggs B, Kilroy C. Stream periphyton monitoring manual. NIWA for Ministry for the Environment. Christchurch. New Zealand 2000; $131 \mathrm{p}$.

15. Edmondson W.T. (ed.).Fresh-water Biology. Second edition. Chapman \& Hall, Limited. London 1959; 1248 p.
16. Whitford L.A, Shumecher G.J. A manual of the fresh-water algae in North Carolina. The North Carolina Agricultural Experiment Station. Tech. Bul. No. 188. Raleigh 1969; 313p.

17. Parra O, González M, Dellarrossa V, Rivera P, Orellana M. Manual taxonómico del fitoplancton en aguas continentales, con especial referencia al fitoplancton de Chile. I Cyanophyceae. Universidad de Concepción. Santiago, Chile 1982; 82 p.

18. Parra O, González M, Dellarrossa V, Rivera P, Orellana M. Manual taxonómico del fitoplancton en aguas continentales, con especial referencia al fitoplancton de Chile. II Crysophyceae-Xanthophyceae. Universidad de Concepción. Santiago, Chile 1982; 70 p.

19. Parra O, González M, Dellarrossa V, Rivera P, Orellana M. Manual taxonómico del fitoplancton en aguas continentales, con especial referencia al fitoplancton de Chile. III Criptophyceae-Dynophyceae- Euglenophyceae. Universidad de Concepción. Santiago, Chile 1982; 99 p.

20. Parra O, González M, Dellarrossa V, Rivera P, Orellana M. Manual taxonómico del fitoplancton en aguas continentales, con especial referencia al fitoplancton de Chile. IV Bacillarophyceae. Universidad de Concepción. Santiago, Chile 1982; 97 p.

21. Parra O, González M, Dellarrossa V, Rivera P, Orellana M. Manual taxonómico del fitoplancton en aguas continentales, con especial referencia al fitoplancton de Chile. $V$ Cholophyceae. Universidad de Concepción. Santiago, Chile 1982; 353 p.

22. Rieradevall M. Atlas de los microorganismos de agua dulce, la vida en una gota de agua. Ediciones Omega S.A. BarcelonaEspaña 1987; 337 p.

23. Cox E. Identification of freshwater diatoms from live material. Chapman \& Hall. London, United Kingdom 1996; 158p.

24. Hauer R, Lamberti G. Methods in stream ecology. Academic Press. The United States of America 1996; 674 p.

25. Underwood A. Experiments in ecology: their logical design and interpretation using analysis of variance. Cambridge University Press. United Kingdom 1997; 504 p.

26. Legendre P, Legendre L. Numerical ecology. Second Edition. Elsevier Science. The Netherlands, Holland 1998; 853 p.

27. Clarke K, Warwick M. Change in marine communities: An approach to statistical analysis and interpretation. Second Edition. PRIMER-E Ltd. United Kingdom 2001; 165p.

28. Cune B, Grace J. Analysis of ecological communities. MjM Software Design. Oregon, United Status 2002; 300p.

29. Álvarez JP, Yepes F. Evaluación trófica del Humedal de Jaboque: Análisis espacial y temporal de las características físico-químicas del agua y de la comunidad planctónica. Convenio ICN/ UNC-EAAB. Investigación aplicada en restauración ecológica del Humedal de Jaboque. Informe final (manuscrito); 2005.

30. Liboriussen L. Production, regulation and ecophysiology of periphyton in shallow freshwater lakes. PhD Thesis. National Environmental Research Institute, Denmark 2003. Version electrónica en: http://afhandlinger.dmu.dk

31. Wetzel R. Limnología Ediciones Omega S.A. Barcelona-España 1981;679 p

32. Pinilla G. Indicadores biológicos en ecosistemas acuáticos continentales de Colombia. Fundación Universidad de Bogotá Jorge Tadeo Lozano, Centro de Investigaciones. Santa fe de Bogotá, Colombia 1998; 67p.

33. Martínez L.F, Donato J. Efectos del caudal sobre la colonización de las algas en un río de alta montaña tropical (Boyacá, Colombia). Caldasia 2003; 25(2): 337-354.

34. Díaz-Quirós C, Rivera-Rondón C.A. Diatomeas de pequeños ríos andinos y su utilización como indicadoras de condiciones ambientales. Caldasia 2004; 26(2):381-394.

35. Newall P, Walsh C.J. Response of epilithic diatom to urbanization influences. Hydrobiologia 2005; 532:53-67. 
36. Burkholder, J. Eutrophication and oligotrophication.. En: Asher S. (ed.) Encyclopedia of biodiversity. Academic Press. United States 2001; 649-670 pp.

37. Kalff J. Limnology-Inland water ecosystem. ISBN 0-13033775-7. Prentice-Hall Inc. Upper Saddle River, New Jersey 07458 USA 2002; 592 p.

38. Pinilla G, Canosa A, Niño J. Gradientes físicos y químicos del fitoplancton de los embalses de Neusa y Prado y la Laguna de Fùquene. (Colombia). Boletín Ecotrópica 2002; 3: 9 -26.

39. Bachmann R.W, Horsburg C.A, Hoyer M.V, Mataraza L.K, Canfield D.E.Jr.Relations between trophic state indicators and plant biomass in Florida Lakes. Hydrobiologia 2002; 470: 219-234.

40. Blinn D, Herbst D. Use of diatoms and soft algae as indicators of environmental determinats in the Lahontan Basin USA. Annual report for California state water resources board. Contractagreement 704558.01.CT776; 2003.

41. Margalef R. Limnología. Ediciones Omega. Barcelona- España 1983; $1010 \mathrm{p}$.
42. Cárdenas G, Florido H. Caracterización de la comunidad fitoplanctónica del Embalse de Chuza: Parque Nacional Natural Chingaza. Cundinamarca-Colombia. Rev. Diógenes 1998; 3(2): $127-166$.

43. Pinilla, G. El papel ecológico de las Euglenófitas en los ecosistemas de agua dulce. La Tadeo 1998; 57:23-29.

44. Margalef R. Ecología. Editorial Omega. Barcelona-España 1991; $951 \mathrm{p}$

45. Rodriguez L, Bicudo D. Similarity among periphyton algal communities in a lentic-lotic gradients of upper Paraná river floodplain, Brazil. Rev. Bras. Bot. 2001; 24(3).

46. Biggs B.J, Smith R.A. Taxonomic richness of stream benthic algae: Effects of flood disturbance and nutrients. Limnol. Oceanogr. 2002; 47(4): 1175-1186.

47. Peterson C.G, Grimm N.B. Temporal variation in enrichment effects during periphyton succession in a nitrogen-limited desert stream ecosystem. Journal of the North American 1992. 